\title{
Application of the Monte Carlo method to estimate the uncertainty in the compressive strength test of high-strength concrete modelled with a multilayer perceptron
}

\section{Estimación de la incertidumbre de un perceptrón multicapa para la modelización del ensayo de resistencia a compresión del concreto de alta resistencia mediante la aplicación del método de Monte Carlo}

Isabel Moromi Nakata (Main and corresponding author)

Facultad de Ingeniería Civil, Universidad Nacional de Ingeniería

Av. Túpac Amaru 210, Lima 25 (Peru)

imoromi@uni.edu.pe

\section{Francisco García Fernández}

Escuela Técnica Superior de Ingeniería de Montes, Forestal y del Medio Natural

Universidad Politécnica de Madrid

Ciudad Universitaria s/n, 28040 Madrid (Spain)

francisco.garcia@upm.es

\section{Ana Torre Carrillo}

Facultad de Ingeniería Civil, Universidad Nacional de Ingeniería

Av. Túpac Amaru 210, Lima 25 (Peru)

anatorre@uni.edu.pe

\section{Pedro Espinoza Haro}

Facultad de Ingeniería Industrial y de Sistemas, Universidad Nacional de Ingeniería Av. Túpac Amaru 210, Lima 25 (Peru)

pcesp67@gmail.com

\section{Luis Acuña Pinaud}

Facultad de Ingeniería Industrial y de Sistemas, Universidad Nacional de Ingeniería Av. Túpac Amaru 210, Lima 25 (Peru)

lacuna@uni.edu.pe

Manuscript Code: 1067

Date of Acceptance/Reception: 25.07.2018/24.01.2018

DOI: 10.7764/RDLC.17.2.319

\begin{abstract}
The use of artificial neural networks as a modeling tool for the physic-mechanical properties of diverse materials has experienced great advances in the last ten years, mainly due to the increased in computing capacities of computers. This technique has been used in many different fields of science and its effectiveness is sufficiently proven. Its application in the particle board industry complies with the requirements of the test regulations for the use in production control, as an alternative method to normalized one. However, in spite of providing a result with a great approximation, they do not indicate anything about the uncertainty of the result. This last point is crucial when the results have to be compared with a product standard. There are internationally accepted deterministic techniques for obtaining the uncertainty of a test result, always starting from the knowledge of the function that relates the measure with the measurement parameters. However, these techniques are not entirely adequate for the case of excessively complex functions such as an artificial neural network. In these cases, the use of stochastic simulation methods such as the Monte Carlo method is more appropriate. In this article, an artificial neural network will be developed to obtain the compressive strength of high-strength concrete to later obtain the uncertainty by a Monte Carlo simulation.
\end{abstract}

Key words: Artificial neural network, compressive strength, high-strength concrete, uncertainty, Monte Carlo, GUM.

\section{Resumen}

La utilización de las redes neuronales artificiales como herramienta de modelización de las propiedades físico-mecánicas de muy diversos materiales ha experimentado un gran avance en los últimos diez años debido principalmente al incremento de las capacidades de cálculo de los ordenadores. Esta técnica ha sido empleada en muy diversos ámbitos de la ciencia y su efectividad está suficientemente acreditada. Su aplicación en la industria de tableros de partículas cumple con los requisitos de las normativas de ensayo para la utilización en el control de producción de métodos alternativos al normalizado. Sin embargo, pese a proporcionar un resultado con una gran aproximación, no indican nada sobre la incertidumbre de dicho resultado. 
Y este último punto es crucial cuando se compara el resultado con la especificación del producto. Existen técnicas deterministas, aceptadas internacionalmente, para la obtención de la incertidumbre de un ensayo, siempre partiendo del conocimiento de la función que relaciona el mensurando con los parámetros de medida. Sin embargo estas técnicas no son del todo adecuadas para el caso de funciones excesivamente complejas como es el caso de una red neuronal artificial. En estos casos es más adecuado la utilización de métodos estocásticos de simulación como el método de Montecarlo. En este artículo se va a desarrollar una red neuronal artificial para la obtención de la resistencia a compresión del concreto para posteriormente obtener la incertidumbre mediante una simulación de Montecarlo.

In recent years, the development of increasingly powerful computers has contributed to an increase in the use of modeling techniques using artificial neural networks in different areas of research. Various applications from home prices valuation (Nuñez Tabares, Rey Carmona \& Caridad y Ocerín, 2013) to engineering (Çanakci, 2007) have benefited from these powerful modeling tools.

These tools provide a substantial improvement over any previously proposed model, regardless of its nature, with the added advantage that they do not need any prior assumption about the statistical structure of data (Khosravi, Nahavandi, Creigton \& Atiya, 2011a).

Major advances have been made in industrial process control, mainly because they are capable of modeling complex relations and can adequately predict whether or not the product characteristics are in line with specifications (Sukthomya \& Tannock, 2005). They have been widely used to characterize different materials such as cement (Baykasoğ, Delhi \& Tanış, 2004), concrete (Bilim, Atiş, Tanyildizi \& Karahan, 2009; Sandemir, 2009; Özcan, Atiş, Karahan, Uncuoğlu \& Tanyildizi, 2009) and certain metals (Mukherjee, Schmauder \& Rühle, 1995; Malinov, Sha \& McKeown, 2001; Hassan, Alrashdan, Hayajneh \& Mayyas, 2009; Ozerdem \& Kolukisa, 2009).

Nevertheless, a neural network itself does not provide any information on confidence intervals or results uncertainty (Khosravi et al., 2011a). This uncertainty is important not only as indicative of measurement process quality, but also provides a confidence interval on results (Solaguren-Beascoa Fernández, Alegre Calderón \& Bravo Díez, 2009).

According to the international accepted definition, the uncertainty associated with a measurement can be defined as the square root of the variance of its probability density function. In this context, the Guide to the Expression of Uncertainty in Measurement (GUM) (BIMP, IEC, IFCC, ISO, IUPAC \& OILM, 1995) indicates a method to obtain the uncertainty on a measurement from the input parameters values and their probability distributions. In most cases, the measurand is derived from a direct measurement, it is not difficult to assess its uncertainty. However, sometimes the measurand is defined as a function of the input values. In these cases, the uncertainty on the measurand can be obtained by the law of propagation of the variances (BIMP et. al, 1995).The use of this methodology implies a knowledge of the function relating the input parameters with the measurand. This is difficult when the model is derived through the numerical solution, for example, in case of models defined by differential equations (Esward, Ginestous, Harris \& Hill, 2007) or when the model is excessively complex and nonlinear, i.e. in the case of an artificial neural network. In these cases, as well in the case of dominant contribution from a non-normal distribution function or when the distribution function of the measurand is asymmetric, an evaluation of the output uncertainty based on the law of propagation of uncertainty will provide values not entirely reliable (Esward et al., 2007).

To solve these problems, the Working Group 1 of the Joint Commitee for Guides in Metrology (JCGM) prepared a supplement to the GUM describing how to obtain the uncertainty on the measured through simulation by the Monte Carlo method (JGCM, 2008). This methodology is generally valid for a larger group of situations than the GUM (Müller et al., 2008).

This article develops a new methodology, based on the simulation by the Monte Carlo method as described in Supplement 1 of the GUM (JGCM, 2008), to evaluate the output uncertainty of a multilayer perceptron used to model the testing for compressive strength of high-strength concrete according to ASTM C 39 / C 39M (ASTM, 2001) with different curing times.

The multilayer perceptron is a type of network widely used to study the mechanical properties of different construction materials, not only cement (Sarıdemir, 2009; Özcan et al., 2009), but also basalt (Çanakci, 2007), various metals (Ozerdem \& Kolukisa, 2009; Reddy, Krishnaiah, Hong \& Lee, 2009) or wood-based panels (Cook \& Chiu, 1997). In all cases, results indicate very good correlations between actual values and those simulated by the neural network. However, none of these studies provide any information on the uncertainty on the network output values. 


\section{High-strength concrete}

This study used 1054 specimens of high-strength concrete made with different types and amounts of cement, sand, coarse aggregate and water. The specimens for compression testing were made according to ASTM standard C 192 / C 192M (ASTM, 2000). Compression tests were carried out according to ASTM standard C39 / C 39M (ASTM, 2001) after different curing times.

Axial compression tests were carried out on a Toni Technik machine with a 3000KN cell and a Tinius Olsen machine with a $1500 \mathrm{KN}$ cell (A). Following the results of similar studies (Torre, García, Moromi, Espinoza \& Acuña, 2015; Acuña, Torre, Moromi \& García, 2014), the explanatory variables chosen to model the compressive strength of concrete were: curing time; type, amount and percentage of additive; type, amount and percentage of microsilica; amounts of water, coarse aggregate, sand and cement; the nominal maximum coarse aggregate size; specific weights of sand and coarse aggregate; and the water-cement ratio.

The Table 1 shows the instruments used for testing, as well as their range of measurement and uncertainty.

\begin{tabular}{lc}
\multicolumn{2}{l}{ Table 1. Instruments used for variables measurements. Source: own elaboration. } \\
\hline Instrument & Uncertainty \\
\hline Sieve3/4" & $0.05 \mathrm{~mm}$ \\
Sieve1" & $0.04 \mathrm{~mm}$ \\
Scale 0-100 kg & $0.02 \mathrm{~kg}$ \\
Scale 0-21000 g & $2.5 \mathrm{~g}$ \\
Vernier0-300 mm & $5 \cdot 10^{-3} \mathrm{~mm}$ \\
\hline
\end{tabular}

\section{Multilayer perceptron}

The multilayer perceptron (Figure 1) could be defined as a computing system that imitates the computational capabilities of biological systems by using a large number of interconnected elements. Its characteristics as a universal approach function (Hornik, 1989) allows the modeling of complex nonlinear relationships.

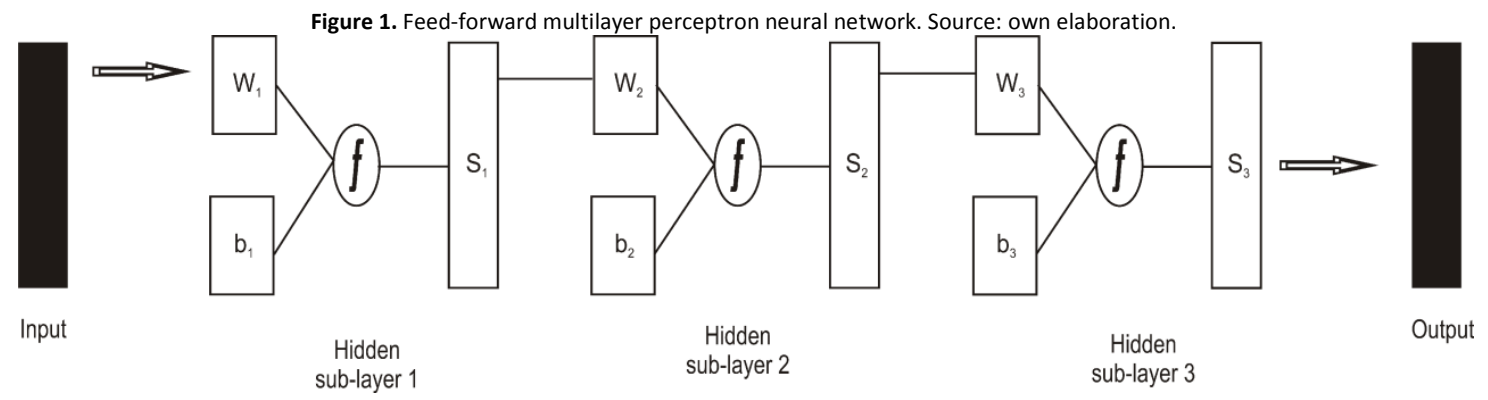

To design a multilayer perceptron is a slow and complex process. There are no fixed rules to establish the internal structure of the network. However, there are a number of recommendations available regarding its design, based on the quantity of available data (Sha, 2007), or on the most desirable type of configuration (Vanstone \& Finnie, 2009). There are as well a number of conditions that must be met to ensure that the network will perform properly, especially concerning the avoidance of overfitting (Bishop, 1995).

To avoid overfitting and to evaluate the reliability of the network, the initial dataset was randomly divided into three subsets: the training, validation and testing subsets. The first two were used for the training phase and for the prevention of overfitting, respectively. The third subset was used to assess the level of reliability of the network (Bishop, 1995).

The sigmoid hyperbolic tangent (Eq. 1) was used as a transfer function; it is mathematically equivalent to the hyperbolic tangent, but improves the network performance (Demuth, Beale \& Hagan, 2002). 


$$
f(x)=\frac{2}{1+e^{(-2 x)}-1}
$$

where:

$f(x)$ : neuron output value.

$x$ : neuron input value.

The values of all variables, both dependent and independent, were normalized to avoid large values of $x$, for which the derivative of $f(x)$ is close to zero. This permits a higher effectiveness of the transfer function (Eq. 2) (Demuth, Beale \& Hagan, 2002).

$$
X^{\prime}=\frac{X-X_{\min }}{X_{\max }-X_{\min }}
$$

where:

$X^{\prime}$ :value after normalization of vector $X$.

$X_{\min } Y X_{\max }$ : maximum and minimum values of vector $X$.

The training algorithm used was the resilient backpropagation, which greatly improves the results with sigmoidal transfer functions (Demuth, Beale \& Hagan, 2002).

Modeling with artificial neural networks can provide output values which closely approximate to the experimental values obtained in laboratory, but it cannot provide an estimation of the uncertainty associated with the output value. This uncertainty is the result, on one hand, of the simplification of the phenomenon by modeling mathematically; and on the other hand, of the variability and noise which are inherent in the input values (Mazloumi, Rose, Currie \& Moridpour, 2011).

Various studies have been undertaken to obtain confidence intervals, but always in particular cases, such as perceptrons with only one hidden layer, with normal distributions of the input variables, or with the assumption of normality of the output errors (Khosravi et, al, 2011a; Papadopoulos, Edwards \& Murray, 2001; Chryssolouris, 1996). These particular cases do not cover the whole field of development of neural networks since they do not consider cases for which the perceptron has more hidden layers (Figure 1) or another type of network.

\section{Calculation of test uncertainty}

The GUM (BIMP et al., 1995) includes a series of international recognized recommendations to evaluate the uncertainty on measurement results. It introduces in particular the law of propagation of uncertainty to obtain the uncertainty on a measurement from the uncertainties of variables involved in the process:

If $y=f\left(x_{1}, x_{2}, \ldots . . . x_{n}\right)$ is the function that determines the final value of the measurement result and $x_{i}(i=1, \ldots ., p)$ are all variables that influence the measurement result, the law of propagation of uncertainty specifies that the combined uncertainty $\left(u^{2} y\right)$ of the final value of the result is defined by (Eq. 3):

$$
\begin{aligned}
& u_{y}{ }^{2}=\left(\frac{\partial y}{\partial x_{1}}\right)^{2} u_{x_{1}}{ }^{2}+\left(\frac{\partial y}{\partial x_{2}}\right)^{2} \cdot u_{x_{2}}{ }^{2}+\ldots \ldots+\left(\frac{\partial y}{\partial x_{j}}\right)^{2} \cdot u_{x_{j}}{ }^{2}+\left(\frac{\partial y}{\partial x_{p}}\right)^{2} \cdot u_{x_{p}}{ }^{2}+\ldots . . \\
& +2 \cdot\left(\frac{\partial y}{\partial x_{1}}\right) \cdot\left(\frac{\partial y}{\partial x_{2}}\right) \cdot u_{x_{1}} \cdot u_{x_{2}} \cdot \gamma\left(x_{1}, x_{2}\right)+\ldots .+2 \cdot\left(\frac{\partial y}{\partial x_{i}}\right) \cdot\left(\frac{\partial y}{\partial x_{j}}\right) \cdot u_{x_{i}} \cdot u_{x_{j}} \cdot \gamma\left(x_{i}, x_{j}\right)+\ldots \\
& +2 \cdot\left(\frac{\partial y}{\partial x_{p-1}}\right) \cdot\left(\frac{\partial y}{\partial x_{p}}\right) \cdot u_{x_{p-1}} \cdot u_{x_{p}} \cdot \gamma\left(x_{p-1}, x_{p}\right)
\end{aligned}
$$

where:

$\mathrm{u}^{2} \mathrm{y}$ : combined test uncertainty

$x_{i}$ : variables influencing the measurement

$\mathrm{u}_{\mathrm{xi}}$ : measurement uncertainty of variable $\mathrm{x}_{\mathrm{i}}$. 
$y=f(x)$ : function relating the measurements with the measurand

$\gamma\left(x_{i}, x_{j}\right)$ : correlation coefficients between variables.

Correlation coefficients between the different variables involved in the process, $v\left(x_{i}, x_{j}\right)$, represent the possible influence that may have one measurement with one instrument, over another measurement performed later with the same instrument or a different one.

\section{The adaptive Monte Carlo method}

The GUM (BIMP et al., 1995) attempts to cover a variety of different situations that can occur during the measurement process. However, in many cases, such as the non-normality of a key input variable, or the complexity of the function relating input and output variables, or the lack of normality of the output errors, using the law of propagation of uncertainty can provide unreliable results (Esward et al., 2007).

The Supplement 1 to the GUM (JGCM, 2008) describes a numerical method based on Monte Carlo simulation to calculate this uncertainty. The number of simulations will depend on the degree of confidence desired for the results. As general rule, $10^{6}$ simulations are usually required to obtain $95 \%$ confidence intervals (JGCM, 2008).

However several factors, such as the nature and type of distribution of the input data, the model function, or the nature itself of output values $Y$, can influence the required number of simulations.

The adaptive Monte Carlo method described in section 7.9 of Supplement 1 (JGCM, 2008) solves this problem by determining the number of simulations through an iterative method based on the desired level of precision for the uncertainty and the required confidence interval:

Let $\delta$ be the acceptance factor, function of the required accuracy (Eq. 4):

$$
\delta=\frac{10^{-n}}{2}
$$

where:

$\mathrm{n}$ : required number of significant digits.

$\delta$ : numerical tolerance factor.

Let $M$ be the number of data for each simulation, function of the required coverage factor (Eq. 5):

$$
M=\operatorname{Max}\left(10^{4}, \quad J\right)
$$

where:

$\mathrm{J}$ : rounding down of $100 /(1-q)$.

q: coverage probability required.

M: number of Monte Carlo trials.

1. Let the parameter $h=1$ be the number of times to repeat the process till the numerical tolerance factor is reached.

2. Randomly the set $X\left(x_{1}, x_{2} \ldots x_{m}\right)$ of $M$ data is generated, to obtain a matrix of dimension $(p \times M)$, where $p$ is the dimension of the input vector (number of input variables) and $M$ the parameter is calculated above. (A)

3. The simulation sequence $h$ of the model is carried out for the M data (Eq. 6).

$$
Y=f(X) \Rightarrow y_{i}=f\left(x_{i}\right)
$$

where:

Y: output vector.

$X$ : input vector.

$\mathrm{f}$ : model function.

4. Starting from $y_{i}(i=1 \ldots M)$, compute for each simulation sequence $h$ :

a. Mean $y^{(h)}$ (Eq. 7). 


$$
y^{(h)}=\frac{1}{M} \sum_{1}^{M} y_{i}
$$

where:

M: number of Monte Carlo trials.

$\mathrm{y}^{(\mathrm{h})}$ : mean of each simulation.

b. Uncertainty $u\left(y^{(h)}\right)$, computed like the standard deviation (Eq. 8).

$$
u\left(y^{(h)}\right)=\sqrt{\frac{1}{M-1} \sum_{1}^{M}\left(y_{i}-y^{(h)}\right)}
$$

where:

M: number of Monte Carlo trials.

$\mathrm{y}^{(\mathrm{h})}$ : mean of each simulation.

$u\left(y^{(h)}\right)$ : uncertainty associated with each $y^{(h)}$.

5. If $h=1$, increase it by 1 and return to step 4 .

6. After each simulation sequence, calculate:

a. Mean and standard deviation of $y^{(h)}$ (Eq. 9).

$$
\begin{gathered}
y=\frac{1}{h} \sum_{1}^{h} y^{(i)} \\
s_{y}=\sqrt{\frac{1}{h \cdot(h-1)} \sum_{1}^{h}\left(y^{(i)}-y\right)^{2}}
\end{gathered}
$$

where:

$\mathrm{h}$ : number of simulation trials.

$\mathrm{y}^{(\mathrm{i})}$ : mean of each simulation trial.

ŷ: mean of all the simulation trials.

Sŷ̀: standard deviation of the simulation trials.

b. Mean and standard deviation of $u\left(y^{(h)}\right)$ (Eq. 10).

$$
\begin{gathered}
u(y)=\frac{1}{h} \sum_{1}^{h} u\left(y^{(i)}\right) \\
s_{u(y)}=\sqrt{\frac{1}{h \cdot(h-1)} \sum_{1}^{h}\left(u\left(y^{(i)}\right)-\hat{u}(y)\right)^{2}}
\end{gathered}
$$

where:

$\mathrm{h}$ : number of simulation trials.

$\mathrm{y}^{(\mathrm{i})}$ : mean of each simulation trial.

$u\left(y^{(i)}\right)$ : uncertainty associated with each simulation $y^{(i)}$.

$\hat{u}(y)$ : meanof the uncertainties associated witheachsimulation.

Sû(y): standard deviation of the uncertainties associated with each simulation.

7. If any of the values of $2 \cdot S_{\hat{y}}$ or $2 \cdot S_{u(\hat{y})}$ is larger than $\delta$, increase $\mathrm{h}$ by 1 and return to step 4 .

The following graph (Figure 2 ) describes the entire process for estimating the uncertainty of the output data in a multilayer perceptron. 


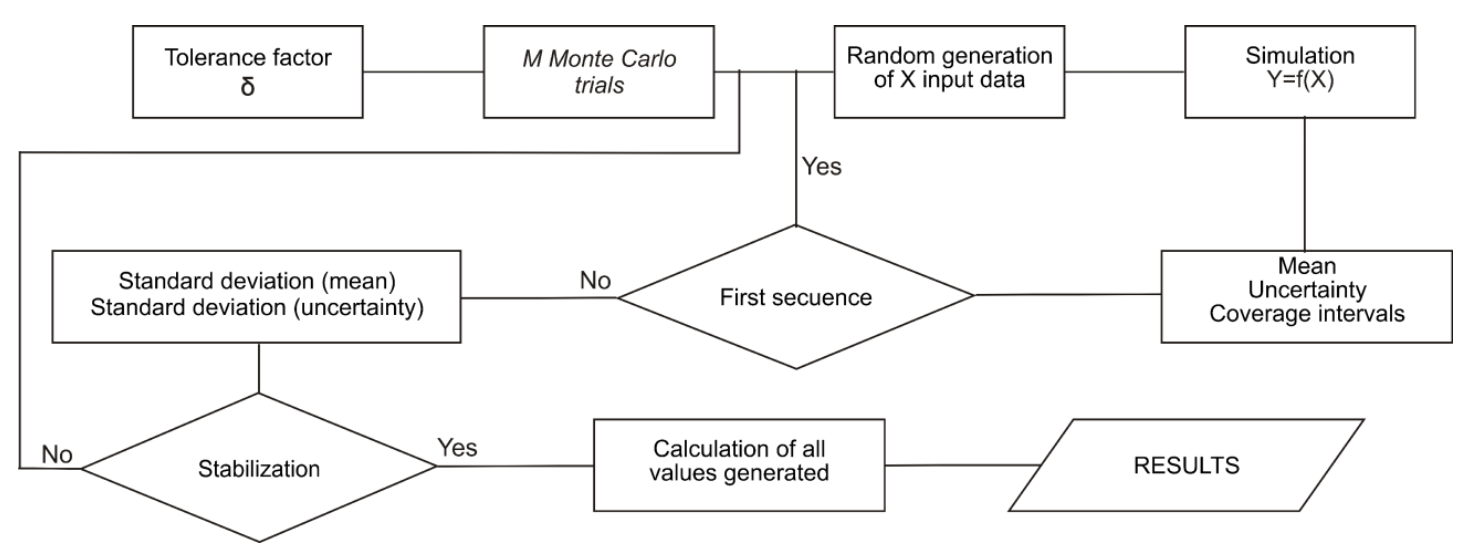

The evaluation of the confidence intervals quality is done with the prediction intervals coverage probability (PICP) (Khosravi et. al, 2011a; Khosravi et al. 2011a; Mazloumi et al., 2011) (Eq. 11) which measures the number of experimental data included within the confidence interval. This measure is a good indicator of the quality of the obtained confidence intervals (Khosravi et al., 2011b).

$$
\begin{gathered}
\operatorname{PICP}(\%)=100 \cdot \frac{1}{n_{\text {test }}} \sum_{1}^{n_{\text {test }}} c_{i} \\
c_{i}=\left\{\begin{array}{ll}
1 & t_{i} \in\left[L_{i}, U_{i}\right] \\
0 & t_{i} \notin\left(L_{i}, U_{i}\right)
\end{array}\right\}
\end{gathered}
$$

where:

$n_{\text {test: }}$ number of experimental data.

$L_{i} y U_{i}$ : lower and upper limits of the confidence intervals of the $i$-th value.

$t_{i}:$ i-thexperimental value.

According to (Mazloumi et al., 2011) and (Khosravi et al., 2010), the PICP is expected to exceed $95 \%$.

All calculations were done with a specific computer program developed in MATLAB.

\section{Uncertainties on the input variables}

Uncertainties on the input and output variables were obtained from the test data calculated according to the propagation of uncertainty Theorem (Eq. 3).

The values obtained for each one of the input parameters and their uncertainties are shown in the following Tables 2 and 3. Those uncertainties are obtained from the calibration certificates of the instruments (Table 1) combined with the heterogeneity uncertainty from the variability of variables.

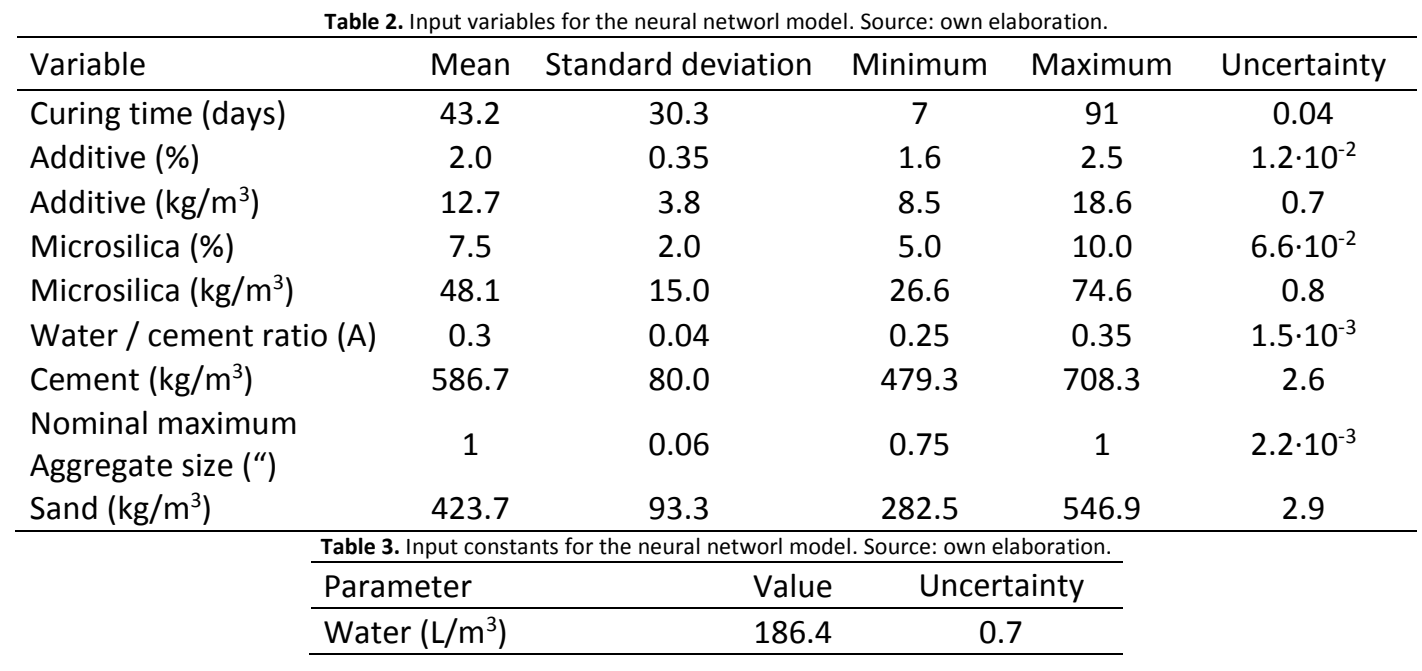




\begin{tabular}{lcc}
\hline $\begin{array}{l}\text { Specific weight of sand } \\
\left(T o n / \mathrm{m}^{3}\right)\end{array}$ & 2.7 & $8.1 \cdot 10^{-4}$ \\
$\begin{array}{l}\text { Coarse aggregate }\left(\mathrm{kg} / \mathrm{m}^{3}\right) \\
\begin{array}{l}\text { Specific weight of coarse } \\
\text { aggregate }\left(T o n / \mathrm{m}^{3}\right)\end{array}\end{array}$ & 1006.2 & 0.7 \\
\hline
\end{tabular}

\section{Artificial neural network}

The optimal architecture for a multilayer perceptron consists of an input layer of 15 variables, two hidden layers with 6 and 1 neuron each and an output of one variable. The results of the training, validation and testing processes can be seen in the Table 4.

\begin{tabular}{|c|c|c|c|c|}
\hline Phase & Structure & $\mathrm{R}^{2}$ & $\mathrm{R}$ & Error (\%) \\
\hline Training & & 0.81 & 0.90 & 4.3 \\
\hline Validation & {$\left[\begin{array}{llll}15 & 6 & 1 & 1\end{array}\right]$} & 0.81 & 0.90 & 4.2 \\
\hline Testing & & 0.80 & 0.89 & 4.2 \\
\hline
\end{tabular}

$\mathrm{R}$ and $\mathrm{R}^{2}$ are de correlation coefficients between experimental data (targets) and simulated data by the neural network (outputs).

Figure 3 shows the correlations between the experimental data and the network results for the testing phase.

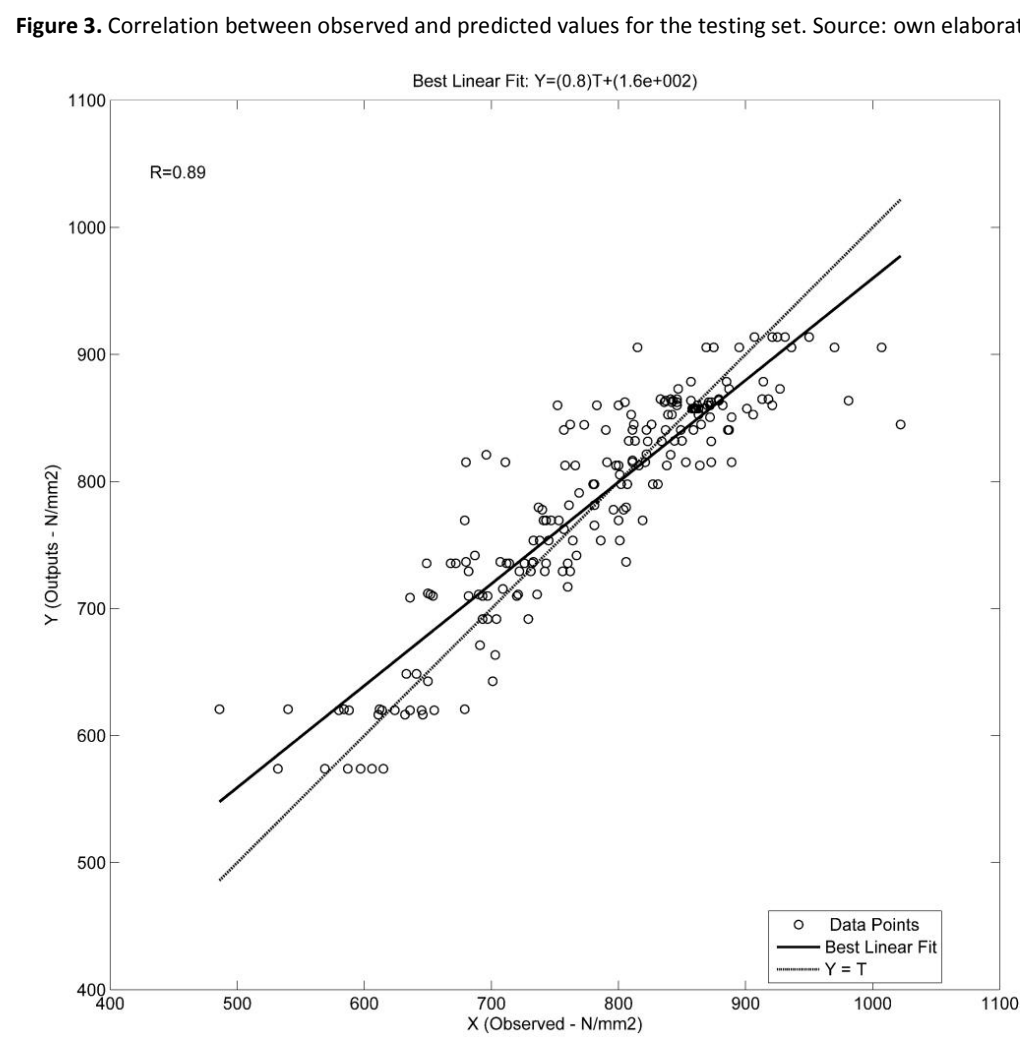

The coefficient of determination of the testing set (Table 4 ) is 0.80 , indicating that the model is able to explain $80 \%$ of the samples variability.

The Table 5 reflects the study of the differences between the experimental values and those obtained by the network for the testing set. 


\begin{tabular}{lccccc}
\multicolumn{6}{l}{ Table 5. ANOVA table comparing experimental results with those obtained by the artificial neural network for the testing set. Source: own elaboration. } \\
\hline Source & SS & d.f. & MS & F & P-value \\
\hline Columns & 1267.2 & 1 & 1267.2 & 0.14 & 0.7 \\
Error & 3445489.8 & 394 & 8744.9 & & \\
Total & 3446756.0 & 395 & & & \\
\hline
\end{tabular}

SS: sums of squares, d.f.: degrees of freedom, MS: mean squares (SS/d.f.), F: Fisher statistic, P-value: p-value for F.

Since $p$-value is greater than 0.05 , there are no significant differences between the experimental values and those obtained by the artificial neural network, at $95 \%$ significance level.

\section{Simulation of the uncertainty through Monte Carlo simulation}

Uncertainty results obtained through the Monte Carlo simulation on the training, validation and testing data sets are shown in the Table 6.

\begin{tabular}{cc} 
Table & 6. PICP for all the data sets. Source: own elaboration. \\
\hline Set & PICP (\%) \\
\hline Training & 98.3 \\
Validation & 98.2 \\
Testing & 97.8 \\
\hline
\end{tabular}

The results obtained with the neural network are within the range of values obtained in other studies of modeling concrete properties. The results obtained with correlation coefficients between 0.90 and 0.91 are consistent with those obtained by other authors (Lee, 2003; Oztas, Pala, Ozbay, Kanka, Caglar \& Bhatti, 2006; Ukrainczyk \& Ukrainczyk, 2008; Ozerdem \& Kolukisa, 2009; Prasad, Eskandari \& Reddy, 2009; Yaprak, Karaci \& Demir, 2013), who obtained correlation coefficients between 0.81 and 0.98 .

Similarly, the determination coefficients $\left(R^{2}=0.80\right.$ and $\left.R^{2}=0.81\right)$ are higher than those reported by Yeh $(1998)$ and similar to those by Ozturan, Kutlu \& Ozturan (2008), who obtained maximum coefficients of 0.78.

The values obtained for PICP are about 98\% (Table 6) indicating that nearly all the experimental data are included within the confidence interval. These values for the PICP are above 95\% level indicated by Mazloumi et al. (2011) and are within ranges obtained by Mazloumi et al. (2011), Khosravi et al. (2011a) or Khosravi et al. (2011b), who obtained confidence intervals between $75 \%$ and $100 \%$, depending on the method used for the simulation.

Our result obtained is better than the result reported in a study of confidence intervals for the forecasts in energy markets (Khosravi et al., 2010), where PICP between $92.6 \%$ and $94.1 \%$ were obtained.

The result is also superior to the one obtained by Shrivastava \& Panigrahi (2013) on a study of confidence intervals for the demand prediction in the electricity market, which obtained a PICP between $50 \%$ and $100 \%$.

It is also higher than results reported by Wan et al. (2014), with 95\% of coverage factor, obtained a PICP between $89.6 \%$ and $99.6 \%$, depending on the modeling method. And it is consistent with the results of Khosravi \& Nahavandi (2014), with obtained PICP values over $95 \%$ with more than 50 simulations.

An artificial neural network has been obtained with a confidence level such that could be used as an alternative to the standard method to predict results of compressive strength of high-strength concrete.

Monte Carlo method has been used to obtain the uncertainty on the output values of an artificial neural network, resulting in confidence level similar to those of other studies.

Therefore, these results have proven the validity of using the Monte Carlo method to simulate the uncertainty in compressive strength values obtained with an artificial neural network. 
The possibility of using artificial neural networks is opened for in-factory control of compressive strength, since the uncertainty associated with the test permits the evaluation of the degree of compliance / non-compliance with a specification when the results are close to the specification limits.

Acknowledgements

This work was supported by the Fondo para la Innovación, la Ciencia y la Tecnología (FINCYT) Project137-FINCYT-IA-2013 (Lima - Perú), the authors acknowledges the General Research Institute of National University of Engineering (IGI-UNI) for its support.

References

Acuña L., Torre A., Moromi I., García F. (2014). Use of artificial neural networks to predict the compressive strength of concrete according to ASTM C39/C 39M standard. Información Tecnológica, 25(4), 3-12.

ASTM. (2000). ASTM C 192/C 192M. Standard Practice for Making and Curing Concrete Test Specimens in the Laboratory, ASTM International, 100 Barr Harbor Drive, PO Box C700, West Conshohocken, PA 19428-2959, United Estates.

ASTM (2001). ASTM C 39/C 39M. Standard Test Method for Compressive Strength of Cylindrical Concrete Specimens, ASTM International, 100 Barr Harbor Drive, PO Box C700, West Conshohocken, PA 19428-2959, United Estates, 2001.

Baykasoğ A., Delhi T., Tanış S. (2004). Prediction of cement strength using soft computing techniques. Cement and Concrete Research, 34, $2083-2090$.

Bilim C., Atiş C.D., Tanyildizi H., Karahan, O. (2009). Predicting the compressive strength of ground granulated blast furnace slag concrete using artificial neural networks. Advances in Engineering Software, 40, 334-340.

BIMP, IEC, IFCC, ISO, IUPAC, OILM. (1995). Guide to the Expression of Uncertainty in Measurement. 2nd edition. International Organisation for Standardisation, Geneva, Switzerland.

Bishop C.M. (1995). Neural networks for pattern recognition. Oxford University Press.

Çanakci H., Pala M. (2007). Tensile strength of basalt from a neural network. Engineering Geology, 94, 10-18.

Chryssolouris G., Lee M, Ramsey A. (1996). Confidence interval prediction for neural network models. IEEE Transaction in Neural Networks, 7(1), 229232.

Cook D.F., Chiu, C.C. (1997). Predicting the internal bond strength of particleboard, utilizing a radial basis function neural network. Engineering Applications of Artificial Intelligence, 10(2),171-177.

Demuth H., Beale M., Hagan M. (2002). Neural Network Toolbox User's Guide, Version 4. The MathWorks Inc., Natick, USA.

Esward T.J., Ginestous A., Harris P.M., Hill I.D. (2007). A Monte Carlo Method for uncertainty evaluation implemented on a distributed computing system. Metrologia, 44, 319-326.

Hassan A.M., Alrashdan A., Hayajneh M.T., Mayyas A.T. (2009). Prediction of density, porosity and hardness in aluminium-cooper-based composite materials using artificial neural network. Journal of Materials Processing Technology, 209, 894-899

Hornik K., Stinchcombe M., White H. (1989). Multilayer feedforward networks are universal approximators. Neural Networks, 2,359-366.

JCGM - Joint Committee for Guides in Metrologyn (2008). Evaluation of measurement data. Supplement 1 to the "Guide to the expression of uncertainty in measurement" - Propagation of distributions using a Monte Carlo method.

Khosravi A., Nahavandi S., Creigton D., Atiya A.F. (2011a). Comprehensive review of neural network-based prediction intervals and new advances. IEEE Transaction in Neural Networks, 22(9), 1341-1356.

Khosravi A., Nahavandi S., Creigton D., Atiya A.F. (2011b). Lower upper bound estimation method for construction of neural networks-based prediction intervals. IEEE Transaction in Neural Networks, 22(3), 337-346.

Khosravi A., Nahavandi S., Creigton D. (2010). Construction of optimal prediction intervals for load forecasting problems. IEEE Transaction on Power Systems, 25(3), 1496-1503.

Khosravi A., Nahavandi S. (2014). An optimized mean variance estimation method for uncertainty quantification of wind power forecasts. International Journal of Electric Power and Energy Systems, 61, 446-454.

Lee S.C. (2003). Prediction of concrete strength using artificial neural networks. Engineering Structures, 25, 849-57.

Malinov S., Sha W., McKeown J.J. (2001). Modelling the correlation between processing parameters and properties in titanium alloys using artificial neural networks. Computational Materials Science, 21, 375-394. 
Mazloumi E., Rose G., Currie G., Moridpour S. (2011). Prediction intervals to account for uncertainties in neural network predictions: Methodology and application in bus travel time prediction. Engineering Applications of Artificial Intelligence, 24(3), 534-542.

Müler M., Wolf M., Rösslein M. (2008). MUSE: computational aspects of a GUM supplement 1 implementation. Metrologia, 45, 586-594.

Mukherjee A., Schmauder S., Rühle M. (1995). Artificial neural networks for the prediction of mechanical behaviour of metal matrix composites. Acta Metallurgica Materialia, 43(11), 4083-4091

Núñez Tabales, J.; Rey Carmona, F.; Caridad y Ocerin, J.M. (2013). Implicit Prices in urban Real Estate valuation. Revista de la Construcción 12(2), 118128.

Özcan F., Atiş C.D., Karahan O., Uncuoğlu E., Tanyildizi H. (2009). Comparison of an artificial neural network and fuzzy logic models for prediction of long-term compressive strength of silica fume concrete. Advances in Engineering Software, 40, 856-863.

Ozerdem M.S., Kolukisa S. (2009). Artificial neural network approach to predict the mechanical properties of Cu-Sn-Pb-Zn-Ni cast alloys. Materials and Design, 30, 764-769.

Oztas A., Pala M., Ozbay E., Kanka E., Caglar A., Bhatti M.A. (2006). Predicting the compressive strength and slum of high strength concrete using neural network. Construction and Building Materials, 20, 769-775.

Ozturan M., Kutlu B., Ozturan T. (2008). Comparison of concrete strength prediction techniques with artificial neural network approach. Building Research Journal, 56, 23-36.

Papadopoulos G., Edwards P.J., Murray A.F. (2001). Confidence estimation methods for neural networks: A practical comparison. IEEE Transactions on Neural Networks, 12(6), 1278-1287.

Prasad B.K.R., Eskandari H., Reddy B.V.V. (2009). Prediction of compressive strength of SCC and HPC with high volume fly ash using ANN. Construction and Building Materials, 23, 117-28.

Reddy N.S., Krishnaiah J., Hong S.G., Lee J.S. (2009). Modeling medium carbon steels by using artificial neural networks. Materials Science and Engineering, 508, 93-105.

Saridemir M. (2009). Prediction of compressive strength of concretes containing metakaolin and silica fume with neural networks. Advances in Engineering Software, 40, 350-355.

Sha W. (2007). Comment on the issues of statistical modelling with particular reference to the use of artificial neural networks. Applied Catalysis. $A$ General, 324, 87-89.

Shrivastava N.A., Panigrahi B.K. (2013). Point and prediction interval estimation for electricity markets with machine learning techniques and wavelet transforms. Neurocomputing, 118, 301-310.

Solaguren-Beascoa Fernández M., Alegre Calderón J.A., Bravo Díez P.M. (2009). Implementation in MATLAB of the adaptative Monte Carlo method for the evaluation of measurement uncertainties. Accreditation and Quality Assurance, 14(2), 95-106.

Sukthomya W., Tannock J. (2005). The training of neural networks to model manufacturing processes. Journal of Intelligent Manufacturing, 16, 3951.

Torre A., García F., Moromi I., Espinoza P., Acuña L. (2015). Prediction of compression strength of high performance concrete using artificial neural networks. Journal of Physics: Conference Series, 582, 1-6.

Ukrainczyk N., Ukrainczyk V. (2008). A neural network method for analysing concrete durability. Magazine of Concrete Research, $60,475-86$.

Vanstone B., Finnie G. (2009). An empirical methodology for developing stockmarket Trading Systems using artificial neural Networks. Expert systems with Applications, 36: 6668-6680.

Wan C., Xu Z., Pinson P., Dong Z.Y., Wong K.P. (2014). Optimal prediction of wind power generation. IEEE Transactions on Power Systems, 29(3), 11661174.

Yaprak H., Karaci A., Demir I. (2013). Prediction of the effect of varying cure conditions and w/c ratio on the compressive strength of concrete using artificial neural networks. Neural Computing and Applications, 22, 133-41.

Yeh I.C. (1998). Modeling of strength of high-performance concrete using artificial neural networks. Cement and Concrete Research, $28,1797-808$. 